\title{
lodine prophylaxis around the Semipalatinsk Nuclear Testing Site, Republic of Kazakstan
}

\author{
Aiko Hamada ${ }^{1}$, Mairash Zakupbekova ${ }^{2}$, Sagadat Sagandikova ${ }^{2}$, Maira Espenbetova $^{3}$, \\ Toshinori Ohashi ${ }^{4}$, Noboru Takamura ${ }^{5}$ and Shunichi Yamashita ${ }^{1, *}$ \\ 'Department of International Health and Radiation Research, Atomic Bomb Disease Institute, Nagasaki University \\ Graduate School of Biomedical Sciences, 1-12-4 Sakamoto, Nagasaki 852-8523, Japan: ${ }^{2}$ Semipalatinsk \\ Diagnostic Center, Republic of Kazakstan: ${ }^{3}$ Semipalatinsk Medical Institute, Republic of Kazakstan: ${ }^{4}$ Pharmaceutical \\ Research Laboratory, Hitachi Chemical Co. Ltd, Ibaragi 317-0061, Japan: ${ }^{5}$ Department of Public Health, Nagasaki \\ University Graduate School of Biomedical Sciences, Nagasaki 852-8523, Japan
}

Submitted 27 March 2003: Accepted 28 May 2003

\begin{abstract}
Objective: This study aimed to clarify the iodine deficiency status in the Semipalatinsk region that has been contaminated by radioactive fallout from nuclear testing during the period of the former USSR.

Design: Based on the Japan-Kazakstan joint project of adult cancer screening around the Semipalatinsk Nuclear Testing Site (SNTS), from May to October 2002 spot urine specimens were collected at random in each village. Separately, children aged 5-15 years from around the SNTS were chosen at random and spot urine specimens were collected from them.

Setting: Area contaminated by radioactive fallout around the SNTS, Republic of Kazakstan.

Subjects: A total of 2609 adults aged $>40$ years from 16 settlements in three regions and one city, and 298 children aged 5-15 years from two regions and one city.

Results: Median urinary iodine concentrations of adults and children in all regions were in the range of $116.0-381.7$ and $127.7-183.0 \mu \mathrm{gl}^{-1}$, respectively. The highest prevalence of values $<50 \mu \mathrm{gl}^{-1}(14.1 \%)$ did not exceed $20 \%$. Distributions within each group, adults and children, showed almost the same pattern, except for one region where more than $50 \%$ of adults had urinary iodine concentration $>100 \mu \mathrm{gl}^{-1}$. Conclusions: In agreement with our previous studies, the urinary iodine concentration data showed no clear evidence of iodine deficiency around the SNTS. Kazakstan is geographically and nutritionally at moderate risk of iodine deficiency disorders without fortification or iodine replacement by iodised salt. The socio-medical prophylaxis against iodine deficiency has been successfully maintained in East Kazakstan.
\end{abstract}

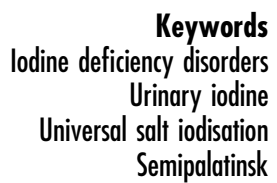

'Radiation and human health' is a major research topic; the consequences for health from the effects of radioactive fallout are a social and political problem in a world that now must bear negative effects from the Cold War $^{1}$. The increased risk of particular cancers among the survivors of the atomic bombing of Hiroshima and Nagasaki, Japan, is well known ${ }^{2,3}$. Recent data also suggest an increased risk of thyroid cancer after the Nevada Nuclear Testing, probably due to the repetitive nature of the radioactive fallout ${ }^{1,4}$. A similar situation can be speculated regarding areas in the former USSR, especially around nuclear testing sites.

Over a period of 13 years from 1949, 26 nuclear tests above ground and 87 in the atmosphere were conducted within the Semipalatinsk Nuclear Testing Site (SNTS),
Kazakstan ${ }^{5}$. There are many small villages, with a population of several hundreds of thousands, scattered in the vast steppe around the site, in an area extremely far from established social and medical infrastructures. Since May 2002, adult cancer screening using a mobile examination vehicle donated by the Japan International Cooperation Agency (JICA) has been undertaken around the SNTS, which is located in the north-eastern part of the Republic of Kazakstan. This screening is a part of a joint project between Japan and Kazakstan to improve healthcare services in the region affected by radioactive fallout as the result of nuclear bomb tests; this was undertaken following an official appeal at the 54th UNDP Congress in New York, 1998. Primary medical screening has been performed for early detection of thyroid, breast 
and lung cancers and leukaemia around the SNTS. Subjects were residents $>40$ years old, who had been indirectly affected by irradiation ${ }^{6}$. Questionnaires including radiation exposure history were taken from all persons who received screening. Blood and urinary analysis, a chest X-ray and ultrasound examination of the thyroid gland and breast were performed in the mobile examination vehicle.

It has been suggested that iodine deficiency might promote the intake of radioactive iodine released from nuclear accidents and nuclear bomb explosions. A dramatic increase in childhood thyroid cancer about 5 years after the nuclear accident in Chernobyl has been reported $^{7}$. This increase might have been due to direct external or internal exposure to short-lived radioactive isotopes such as ${ }^{131} \mathrm{I}$ and ${ }^{133} \mathrm{I}$ as occurred just after the Chernobyl nuclear accident ${ }^{8}$. However, there are no reliable data concerning the iodine status of the population and the prevalence of goitre at the time of the accident; a national programme to prevent iodine deficiency had not functioned well in this area during the 1970s and 1980s?.

In contrast, Kazakstan, part of the former USSR, is classified as an iodine-deficient country ${ }^{10}$. Median urinary iodine concentration $<100 \mu \mathrm{gl}^{-1}$ was found in $65 \%$ of 494 samples, and only $29 \%$ of households consumed iodised salt in $1999^{11}$. In 2001 we undertook a preliminary investigation of urinary iodine concentrations and thyroid abnormalities of schoolchildren in areas around the SNTS, where no iodine deficiency and a rate of less than $1.0 \%$ for goitre were ascertained ${ }^{12}$. We have since attempted to confirm this result on a larger scale by performing urinary iodine measurements as part of an adult cancer-screening programme around the SNTS.

\section{Subjects and methods}

\section{Subjects}

Subjects came from eight settlements in the Abai district (Karaaul, Kockbay, Kunduz, Arhat, Kaskabulak, Sarjar, Toktams, Medeo) and six settlements in the Abraly district (Kainar, Abraly, Ackbulack, Dogolan, Aynabulak, Tanat), two settlements in the Jana-Semey district (Checkoman, Novo-Pokrov) and from Semipalatinsk City. Any resident aged $>40$ years could partake of medical screening for this study.

Medical screening was performed from May to October 2002, as a JICA project between Japan and Kazakstan, in highly radio-contaminated areas within $100 \mathrm{~km}$ of the SNTS. To minimise evaluation errors, we followed a recommended sampling protocol ${ }^{13}$. A minimum of 50 , and optimally more than 100, casual spot urine samples for general urine examination were collected at random in each village. However, in Tanat village, fewer than 50 samples were collected. The sampling time was during the morning, and there was no restriction of food before sampling. All samples were kept at $4{ }^{\circ} \mathrm{C}$ until assay. We analysed a total of 2609 spot adult urine samples at the Regional Diagnostic Center in Semipalatinsk.

Independent of this medical screening, a total of 298 children aged 5-15 years were chosen at random in three regions (Semipalatinsk City, Beskaragay and Kokpekty districts) and spot urine specimens collected from them. Beskaragay district is on the north-east border of the SNTS; Kokpekty, an area known to be uncontaminated by radioactive fallout, is located $250 \mathrm{~km}$ away on the southeast of the SNTS.

\section{Measurement of urinary iodine}

The urinary iodine concentration was measured by a modified 'simple microplate method'14, based on the Sandell-Kolthoff reaction, which incorporates both the digestion and the reaction into a microplate format. Briefly, using a specially designed sealing cassette (Atom Kousan Co. Ltd, Tokyo) to prevent loss of vapour and cross-contamination among plates, ammonium persulphate digestion was performed in a 96-well microplate in a standard oven at $90^{\circ} \mathrm{C}$ for $90 \mathrm{~min}$. Samples were then transferred to another microplate and the reduction reaction of ceric ammonium sulphate carried out at $25^{\circ} \mathrm{C}$ for $30 \mathrm{~min}$, with results being read on a microplate reader at $405 \mathrm{~nm}$. The sensitivity of this method was $>10 \mu \mathrm{gl}^{-1}$.

We expressed urinary iodine concentrations in $\mu \mathrm{gl}^{-1}$, not related to creatinine, because the urinary iodine excretion of individuals can show day-to-day and withinday variation; however, spot urinary iodine concentrations give useful information in population samples of appropriate size for cross-sectional epidemiological survey ${ }^{15}$.

As epidemiological criteria for assessing the severity of iodine deficiency, we adopted the proposals by the World Heath Organization, the United Nations Children's Fund and the International Council for the Control of Iodine Deficiency Disorders based on median urinary iodine concentration. Median urinary iodine concentration of $<20 \mu \mathrm{gl}^{-1}$ is defined as indicative of severe iodine deficiency disorders (IDD), 20-49 $\mu \mathrm{gl}^{-1}$ as moderate IDD, $50-99 \mu \mathrm{gl}^{-1}$ as mild IDD and $\geq 100 \mu \mathrm{gl} l^{-1}$ as no IDD $^{16}$.

\section{Results}

Table 1 summarises median urinary iodine concentrations and presents the percentages of the samples showing values $<50$ and $<20 \mu \mathrm{gl}^{-1}$. Median urinary iodine concentrations of adults and children in all villages were in the range of $116.0-381.7$ and $127.7-183.0 \mu \mathrm{gl}^{-1}$, respectively. Even the highest prevalence of median urinary iodine concentration $<50 \mu \mathrm{gl}^{-1}$, observed in children in the Beskaragay district (14.1\%), did not exceed $20 \%$. Distributions of urinary iodine concentration, in both adults and children, showed almost same patterns, except for adults in one village (Kaskabulak) (Figs 1 and 2). 
Table 1 Median urinary iodine concentrations and percentage of the samples showing values $<50$ and $<20 \mu \mathrm{gl}^{-1}$

\begin{tabular}{|c|c|c|c|c|c|}
\hline Region & Village & Number & $\begin{array}{l}\text { Median urinary iodine } \\
\text { concentration }\left(\mu \mathrm{gl}^{-1}\right)\end{array}$ & $\begin{array}{c}\text { Median urinary iodine } \\
\text { concentration }<50 \mu \mathrm{gl}^{-1}(\%)\end{array}$ & $\begin{array}{l}\text { Median urinary iodine } \\
\text { concentration } \\
<20 \mu \mathrm{gl}^{-1}(\%)\end{array}$ \\
\hline \multicolumn{6}{|l|}{$\operatorname{ADULTS}(n=2609)$} \\
\hline \multirow[t]{8}{*}{ Abai } & Karaaul (including Kingirbay) & 72 & 234.0 & 0.0 & 0.0 \\
\hline & Kockbay & 156 & 181.7 & 6.4 & 2.6 \\
\hline & Kunduz & 200 & 171.9 & 8.0 & 0.5 \\
\hline & Arhat & 246 & 197.2 & 4.7 & 0.0 \\
\hline & Kaskabulak & 215 & 381.7 & 0.0 & 0.0 \\
\hline & Sarjar & 151 & 246.9 & 1.3 & 0.0 \\
\hline & Toktams & 194 & 207.3 & 2.6 & 0.0 \\
\hline & Medeo & 66 & 250.9 & 3.0 & 1.5 \\
\hline \multirow[t]{6}{*}{ Abraly } & Kainar & 148 & 202.5 & 2.7 & 0.0 \\
\hline & Abraly & 170 & 191.1 & 2.9 & 0.0 \\
\hline & Ackbulack & 118 & 232.6 & 4.2 & 0.9 \\
\hline & Dogolan & 201 & 196.7 & 2.5 & 0.5 \\
\hline & Aynabulak & 58 & 172.5 & 1.7 & 0.0 \\
\hline & Tanat & 42 & 173.7 & 11.9 & 0.0 \\
\hline \multirow{2}{*}{ Jana-Semey } & Checkoman & 294 & 197.0 & 4.7 & 0.6 \\
\hline & Novo-Pokrov & 79 & 201.7 & 3.8 & 2.5 \\
\hline Semipalatinsk City & & 199 & 116.0 & 6.5 & 0.0 \\
\hline Average & & & 209.1 & 3.9 & 0.5 \\
\hline \multicolumn{6}{|c|}{ CHILDREN $(n=298)$} \\
\hline Semipalatinsk City & - & 99 & 127.7 & 8.1 & 1.0 \\
\hline Beskaragay & - & 99 & 149.4 & 14.1 & 2.0 \\
\hline Kokpekty & - & 100 & 183.0 & 5.0 & 3.0 \\
\hline Average & & & 153.4 & 9.6 & 2.5 \\
\hline
\end{tabular}

Comparison with data from Gomel, Belarus ${ }^{17}$, where the median urinary iodine concentration is $47.3 \mu \mathrm{g} \mathrm{l}{ }^{-1}$, reveals good iodine status of the population in the area of iodine prophylaxis around the SNTS (Fig. 3). More than $50 \%$ of the population in each group had median urinary iodine concentration $\geq 100 \mu \mathrm{gl} \mathrm{l}^{-1}$.

\section{Discussion}

IDD include all illnesses related to iodine deficiency, such as goitre, abortion, stillbirth, neonatal and other types of hypothyroidism, foetal brain damage of varying degrees and cretinism, which can be prevented by a sufficient

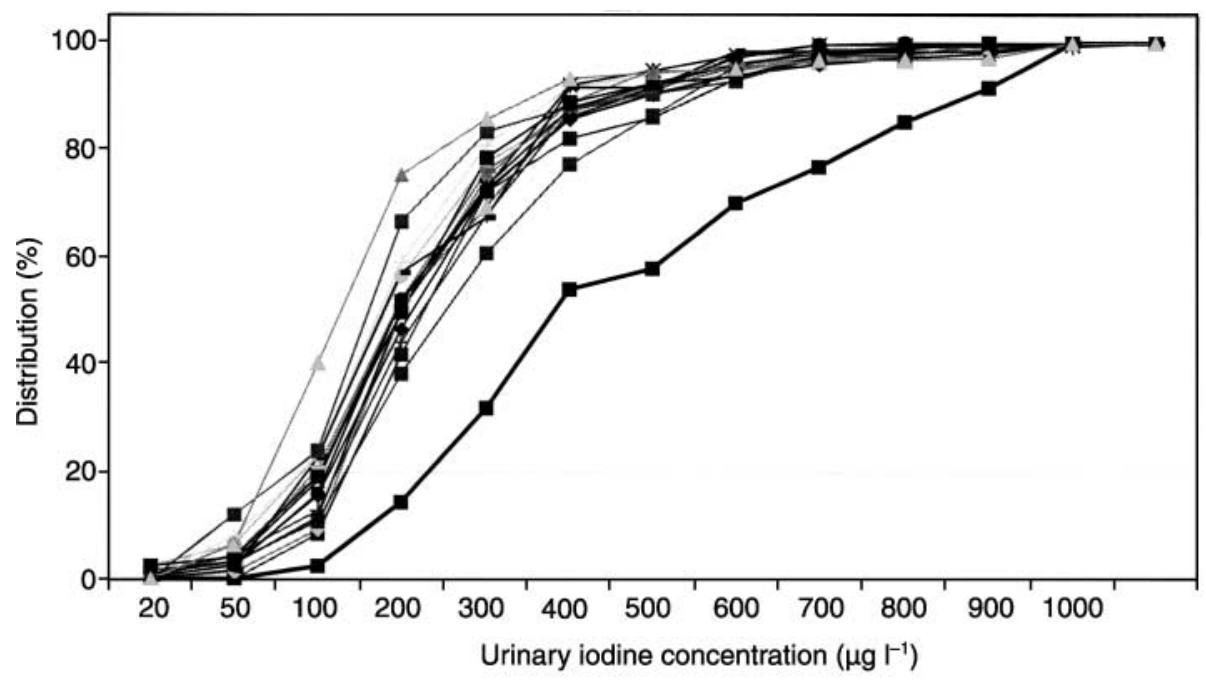

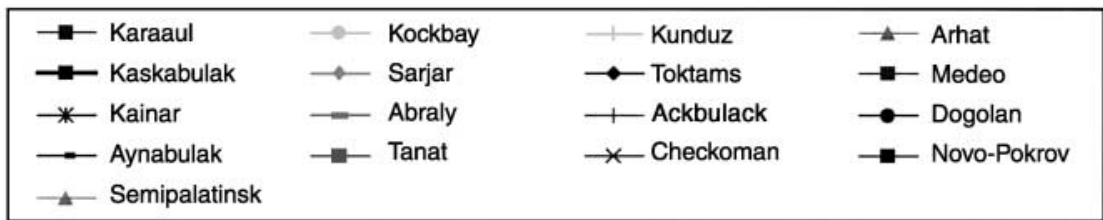

Fig. 1 Distribution of urinary iodine concentration in adults aged $>40$ years 


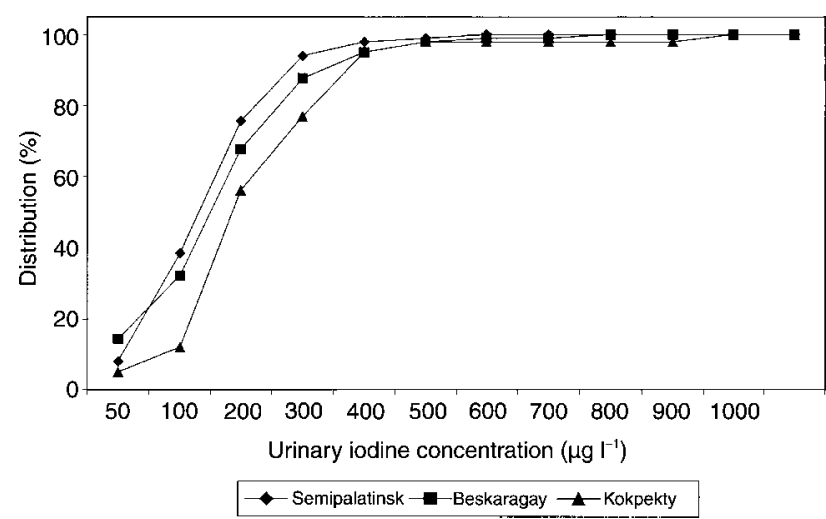

Fig. 2 Distribution of urinary iodine concentration in children aged $5-15$ years

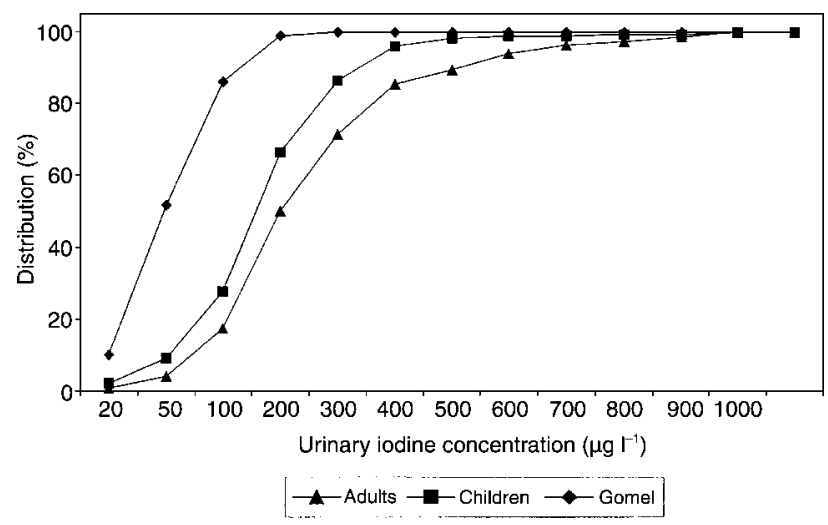

Fig. 3 Distribution of urinary iodine concentration in adults and children around the Semipalatinsk Nuclear Testing Site, Republic of Kazakstan, compared with that in Gomel, Belarus ${ }^{17}$

intake of iodine. Recognition of IDD has resurfaced since the 1990s, and many programmes to eliminate IDD have been initiated around the world, especially after the catastrophe in the former USSR at Chernobyl. Universal salt iodisation is the main strategy of these programmes. Iodine control programmes were undertaken throughout the country with highly successful results ${ }^{18}$.

In the former USSR, scientists since the 1940s have suggested a strategy to eradicate endemic goitre by compulsory iodine prophylaxis. Prevention and control of endemic goitre were carried out except for a few years during and after World War II, and iodine deficiency had been almost eliminated by the 1970s. The prevalence of goitre decreased dramatically, and the most serious complications, such as cretinism and large nodular goitre, had almost disappeared ${ }^{9}$. However, the political changes and social upheaval following the break-up of the former Soviet block must be held responsible for the subsequent failure of iodine prophylaxis. The lack of a continuous monitoring system caused a dramatic drop in salt iodisation rates. Iodine nutritional status at the time of exposure to radioactive iodine strongly affects the thyroid radiation dose, because of its effects on thyroid iodine uptake and thyroid volume. Iodine deficiency may increase the risk of radiation-induced thyroid tumourigenesis. Indeed, we previously reported data suggesting an incompleteness of the iodine supply for iodine prophylaxis around Chernobyl ${ }^{19}$. In universal salt iodisation programmes, the importance of monitoring and evaluation is now well recognised ${ }^{20,21}$.

There are many small villages scattered in the vast territory of Kazakstan, which covers steppe, desert and forest, far from any ocean. The climate is severe for residents and the soil shows low iodine levels in most $\operatorname{areas}^{10}$. Without proper fortification of iodine, Kazakstan would have a moderate risk of iodine deficiency. Because of its vast size and poor accessibility, monitoring of iodine deficiency is extremely difficult to undertake. Regarding iodine deficiency in adults, the thyroid status of pregnant and lactating women aged $15-44$ years is of greatest concern ${ }^{22}$. Although we could not examine this population group in particular, a sufficient number of adult urine samples in this study gives us useful information about the general iodine status around the SNTS.

Our JICA project to improve healthcare services in this area contaminated by radioactive fallout will continue for another 2 years. Furthermore, establishment of a database system of medical screening will give us more direct information on the relationship between radiation exposure and health.

In conclusion, the current situation of iodine nutrition around the SNTS indicates good supplementation. However, continuing attention to iodine nutrition in long-term studies is essential, and there is a need to monitor the potential influence of iodine status on the development of benign and malignant thyroid tumours in response to irradiation or other insults.

\section{Acknowledgements}

This study was partially supported by the Japan International Cooperation Agency under the mutual agreement of the Japanese Government and the Minister of Health, Kazakstan.

\section{References}

1 Gilbert ES, Land CE, Simon SL. Health effects from fallout. Health Physics 2002; 82(5): 726-35.

2 Nagataki S, Shibata Y, Inoue S, Yokoyama N, Izumi M, Shimaoka K. Thyroid diseases among atomic bomb survivors in Nagasaki. Journal of the American Medical Association 1994; 272(5): 364-70.

3 Thompson DE, Mabuchi K, Ron E, Soda M, Tokunaga M, Ochikubo S, et al. Cancer incidence in atomic bomb survivors. Part II: solid tumors, 1958-1987. Radiation Research 1994; 137(Suppl. 2): S17-67.

4 Robbins J, Schneider AB. Thyroid cancer following exposure to radioactive iodine. Reviews in Endocrine \& Metabolic Disorders 2000; 1(3): 197-203. 
5 Yamamoto M, Tsukatani T, Katayama Y. Residual radioactivity in the soil of the Semipalatinsk Nuclear Test Site in the former USSR. Health Physics 1996; 71(2): 142-8.

6 Simon SL, Bouville A. Radiation doses to local populations near nuclear weapons test sites worldwide. Health Physics 2002; 82(5): 706-25.

7 Kazakov VS, Demidchik EP, Astakhova LN. Thyroid cancer after Chernobyl. Nature 1992; 359(6390): 21.

8 Shibata Y, Yamashita S, Masyakin VB, Panasyuk GD, Nagataki S. 15 years after Chernobyl: new evidence of thyroid cancer. Lancet 2001; 358(9297): 1965-6.

9 Dedov II. Endemic goiter in the former USSR: problems and solutions. IDD Newsletter 1992; 8(1): 2-4.

10 Zelster ME, Aidarkhanov BA, Berezhnaya IM, Speransly GG, Bazarbekova RB, Nurbetova AA, et al. Iodine deficiency and its clinical manifestations in Kazakhstan. IDD Newsletter 1992; 8(1): 10-2.

11 Gerasimov G. IDD in Eastern Europe and Central Asia. IDD Newsletter 2002; 18(3): 33-7.

12 Hamada A, Takamura N, Meirmanov S, Alipov G, Mine M, Ruslan E, et al. No evidence of radiation risk for thyroid gland among schoolchildren around Semipalatinsk Nuclear Testing Site. Endocrine Journal 2003; 50(1): 85-9.

13 Bourdoux P. Evaluation of the iodine intake: problems of the iodine/creatinine ratio - comparison with iodine excretion and daily fluctuations of iodine concentration. Experimental and Clinical Endocrinology \& Diabetes 1998; 106(Suppl. 3): S17-20.

14 Ohashi T, Yamaki M, Pandav CS, Karmarkar MG, Irie M. Simple microplate method for determination of urinary iodine. Clinical Chemistry 2000; 46(4): 529-36.

15 Soldin OP. Controversies in urinary iodine determinations. Clinical Biochemistry 2002; 35(8): 575-9.
16 World Health Organization (WHO)/United Nations Children's Emergency Fund (UNICEF)/International Council for the Control of Iodine Deficiency Disorders (ICCIDD). Indicators for Assessing Iodine Deficiency Disorders and their Control Through Salt Iodization. WHO/NUT/94.6. WHO/UNICEF/ICCIDD, 1994 [unpublished].

17 Ishigaki K, Namba H, Takamura N, Saiwai H, Parshin V, Ohashi T, et al. Urinary iodine levels and thyroid diseases in children; comparison between Nagasaki and Chernobyl. Endocrine Journal 2001; 48(5): 591-5.

18 Francois D, Burgi H, Chen ZP, Dunn JT. World status of monitoring iodine deficiency disorders control programs. Thyroid 2002; 12(10): 915-24.

19 Ashizawa K, Shibata Y, Yamashita S, Namba H, Hoshi M, Yokoyama $\mathrm{N}$, et al. Prevalence of goiter and urinary iodine excretion levels in children around Chernobyl. Journal of Clinical Endocrinology and Metabolism 1997; 82(10): 3430-3.

20 Gerasimov G. The challenge ahead: iodized salt on every table for ever. Bulletin of the World Health Organization 2002; 80(8): 413-4.

21 Robbins J, Dunn JT, Bouville A, Kravchenko VI, Lubin J, Petrenko S, et al. Iodine nutrition and the risk from radioactive iodine: a workshop report in the Chernobyl Long Term Follow-Up Study. Thyroid 2001; 11(5): 487-91.

22 World Health Organization (WHO)/United Nations Children's Emergency Fund (UNICEF)/International Council for the Control of Iodine Deficiency Disorders (ICCIDD). Assessment of Iodine Deficiency Disorders and Monitoring their Elimination. WHO/NUT/01.1. WHO/UNICEF/ICCIDD, 2001 [unpublished]. 